\title{
Association between extreme autistic traits and intellectual disability: insights from a general population twin study
}

\author{
R. A. Hoekstra, F. Happé, S. Baron-Cohen and A. Ronald
}

\section{Background}

Autism is associated with intellectual disability. The strength and origin of this association is unclear

\section{Aims \\ To investigate the association between extreme autistic traits and intellectual disability in children from a community-based sample and to examine whether the association can be explained by genetic factors. \\ Method \\ Children scoring in the extreme $5 \%$ on measures of autistic traits, IQ and academic achievement were selected from 7965 7/8-year-old and 3687 9-year-old twin pairs. Phenotypic associations between extreme autistic traits and intellectual disability were compared with associations among the full-range scores. Genetic}

correlations were estimated using bivariate DeFries-Fulker extremes analyses.

\section{Results}

Extreme autistic traits were modestly related to intellectual disability; this association was driven by communication problems characteristic of autism. Although this association was largely explained by genetic factors, the genetic correlation between autistic traits and intellectual disability was only modest.

\section{Conclusions}

Extreme autistic traits are substantially genetically independent of intellectual disability.

\section{Declaration of interest}

None.
Intellectual disability (here defined as $\mathrm{IQ}<70$ ) is common in autism. Historically, the prevalence of intellectual disability in autism is estimated at $70 \%,{ }^{1}$ but recent studies encompassing all autism-spectrum conditions, including Asperger syndrome and pervasive developmental disorder - not otherwise specified, suggest that the prevalence of intellectual disability in autismspectrum conditions may be considerably lower. ${ }^{2,3}$ It has been suggested that the association between autism and intellectual disability may be inflated because of clinical ascertainment bias. ${ }^{4}$ If this hypothesis holds true it has implications for studying the causes of autism-spectrum conditions. A strong genetic link between autism-spectrum conditions and intellectual disability would argue for a search for genes influencing both traits. A limited association would argue for separate genetic influences on each trait. A possible ascertainment bias for intellectual disability in autism-spectrum conditions limits the investigation of this association in clinical samples. Instruments that assess autistic traits on a quantitative scale ${ }^{5,6}$ enable studying the relationship in population samples. This study reports on the association between autistic traits, IQ and academic achievement in the extreme $5 \%$ scorers of a large community-based twin sample. The genetic informative design allowed for exploration of the genetic and environmental origin of the association.

\section{Method}

\section{Participants}

Participants were part of the longitudinal Twins Early Development Study (TEDS), a child twin sample representative of the general population in the UK. ${ }^{7,8}$ The sample characteristics of TEDS are described elsewhere. ${ }^{9}$ Zygosity in same-sex twins was determined using polymorphic DNA markers $(75 \%$ of participants) or a parent-report questionnaire that has a reported accuracy of $95 \% .{ }^{10}$ Participants' IQ and academic achievement were assessed at ages 7 and 9. Measures of autistic traits were collected when the twins were nearly 8 (parent report) and 9 (teacher report) years.

Exclusion criteria were as follows: no first contact data available (153 families); extreme pregnancy or perinatal difficulties (165 families); unclear twin zygosity (300 families); not having English as the spoken first language (146 families); specific medical syndrome (not including suspected autism-spectrum conditions) such as Down syndrome (225 families). After exclusions data were available for 8104 twin pairs, of which 1340 were monozygotic male pairs, 1325 dizygotic males, 1496 monozygotic females, 1354 dizygotic females and 2589 dizygotic twin pairs of opposite sex. At age 9, only twins born between January 1994 and August 1995 were contacted, resulting in a smaller sample size. Data on IQ, academic achievement and/or autistic traits were available for $79657 / 8$-year-old twin pairs and for 3687 pairs at age 9 .

\section{Measures}

The Childhood Autism Spectrum Test $(\mathrm{CAST})^{5}$ is a 31 -item questionnaire asking about behaviours associated with autismspectrum conditions. A CAST score of $\geqslant 15$ is the cut-off for identifying children at risk for autism-spectrum conditions. Items can be divided into three subscales, ${ }^{11}$ based on the DSM-IV criteria $^{12}$ for autism: social impairments (12 items); communication impairments (12 items); and restricted repetitive behaviours and interests $(7$ items). The CAST shows good test-retest reliability $(r=0.83)^{13}$ and satisfactory internal consistency $(\alpha=0.73$ in TEDS) for the full CAST and moderate $\alpha$-values for the subscales (social impairments: $\alpha=0.57$; communication impairments: $\alpha=0.66$; restricted repetitive behaviours and interests: $\alpha=0.50$ ). Parents rated the child's autistic traits at age 8 . If the families gave consent, teachers were asked to complete an abbreviated version of the CAST $(20 \text { items })^{8}$ when the twins were 9 years. 
A battery of IQ tests was administered by telephone at age 7 . Two verbal (similarities and vocabulary) and two non-verbal subtests (picture completion and conceptual grouping) from the Wechsler Intelligence Scale for Children-III (WISC-III) ${ }^{14}$ and the McCarthy Scales of Children's Abilities ${ }^{15}$ were modified for telephone administration. The IQ composite score derived from the telephone-administered test battery correlates 0.72 with the Stanford-Binet Intelligence Scale. ${ }^{16}$ At age 9, IQ was assessed using test booklets completed by the twins under parental supervision. A composite score was derived from two verbal (adaptations of the WISC-III vocabulary and information subtests) and two non-verbal tests (adaptations of the subtests figure classification and figure analogies from the Cognitive Abilities Test 3). ${ }^{17}$

Teachers were asked to assess the twin's academic achievement using a 5-point rating scale following the UK national curriculum achievement goals. A composite score was used at both ages, based on achievement in English and mathematics at age 7 and in English, mathematics and science at age 9 .

\section{Children with autism-spectrum conditions}

Children at risk for autism-spectrum conditions were identified from parents informing TEDS about their twins' diagnoses or from scores above the cut-off on the CAST at age 8. These children were followed up and were administered the Development and Well-Being Assessment (DAWBA). ${ }^{18}$ Based on the data available at the time of the present analyses, 85 children were identified with the DAWBA as having autism, 11 children with Asperger syndrome, and 64 children with autism-spectrum conditions other than autism or Asperger syndrome. Parent-rated CAST scores were available for 145 of these children (75 with autism; 10 with Asperger syndrome; 60 with other autism-spectrum conditions). Data on IQ and academic achievement were available for 51 and 84 children at age 7 respectively. Most children with autism-spectrum conditions were not invited to participate at age 9 to avoid overtesting, as these children were enrolled in another project during this time.

\section{Data analyses}

Children scoring in the top $5 \%$ of the distribution of autistic traits and/or in the bottom 5\% of the distribution of IQ and academic achievement scores were defined as extreme cases (probands). This cut-off was chosen as the best balance between the need for a sufficient sample size and the aim of studying extreme groups. All analyses were based on age- and sex-regressed scores.

To examine whether children with extreme autistic traits were at increased risk for intellectual disability (as indexed by low IQ/ academic achievement), chi-square tests were performed for one randomly selected twin from each pair. The phenotypic correlations across the full-range scores were examined using structural equation modelling in $\mathrm{Mx}$ for Windows, ${ }^{19}$ taking into account the genetic relatedness between the twins. Phenotypic correlations indicate whether variation in trait $X$ covaries with individual differences in trait $Y$. Phenotypic group correlations examine the extent to which extreme scorers on trait $X$ as a group score above or below the population mean on unselected trait $Y .{ }^{20}$ Phenotypic group correlations are calculated by dividing the proband's standardised score on the unselected variable $Y$ by the proband's standardised score on the selected variable $X$. A phenotypic group correlation of 1.0 indicates that the probands' mean score on $Y$ is as extreme as the probands' mean score on $X$; a phenotypic group correlation of 0.0 means that the probands' score on $Y$ is no different from the population mean. Phenotypic group correlations are bidirectional: selecting probands for extreme autistic traits and examining their IQ score could yield different results from selecting probands for extremely low IQ and examining their CAST scores.

\section{Genetic analyses}

DeFries-Fulker extremes analysis ${ }^{21}$ is a regression analysis of twin data in which the co-twin's mean score is predicted by their proband's score, taking into account the genetic relatedness between the twins (1.0 for monozygotic (MZ) twins; on average 0.5 for dizygotic (DZ) twins). Rather than assessing a dichotomy (e.g. intellectual disability present or absent), DeFries-Fulker extremes analysis assesses the continuous distribution directly and thereby provides a powerful test of the aetiology of extreme scores on a continuous dimension.

Sex differences are reported for autism. To maintain the comparability of the MZ and DZ pairs, DeFries-Fulker extremes analyses were carried out on data from same-sex DZ twins only. Prior to the regression analysis all scores were standardised (i.e. expressed as a deviation from the population mean) and then transformed (i.e. divided by the difference between the proband and general population means, specific for each zygosity). Comparing the regression to the population mean for $\mathrm{MZ}$ and $\mathrm{DZ}$ co-twins of probands gives insight in the genetic influences on extreme traits. If the mean scores of MZ co-twins resemble the proband scores more closely than DZ co-twin scores do there is evidence for genetic effects on the extreme trait.

The following regression equation is used in DeFries-Fulker extremes analyses:

$$
C=B_{1} P+B_{2} R+A,
$$

in which $C$ is the predicted score for the co-twin, $P$ is the proband score, $R$ is the coefficient of the genetic relatedness between the twins and $A$ is the regression constant; $B_{1}$ is the partial regression of the co-twin's score on the proband's score and is an index of average $\mathrm{MZ}$ and $\mathrm{DZ}$ resemblance independent of zygosity and $B_{2}$ is the partial regression of the co-twin's score on $R$ and is equivalent to twice the difference between the standardised transformed means for $\mathrm{MZ}$ and $\mathrm{DZ}$ co-twins. The value of $B_{2}$ provides a direct estimate of group heritability $\left(h_{\mathrm{g}}^{2}\right)$ : the extent to which genetic factors account for the mean difference between probands and the population.

The aetiology of the association between extreme autistic traits and low IQ/academic achievement was studied using the bivariate extension of DeFries-Fulker analysis. ${ }^{22}$ Bivariate DeFries-Fulker analysis selects the probands on trait $X$, but compares the quantitative scores of their co-twins on unselected trait $Y$. In the bivariate DeFries-Fulker regression equation:

$$
C_{Y}=B_{1} P_{X}+B_{2} R+A,
$$

$C$ is the predicted score of the co-twin on unselected variable $Y, P$ is the proband's score on selected variable $X, B_{1}$ is the partial regression of the co-twin's $Y$ score on the proband's $X$ score, and $B_{2}$ is the partial regression of the co-twin's $Y$ score on the coefficient of the genetic relatedness. The value of $B_{2}$ indicates the extent to which the proband's deficit on trait $X$ can be ascribed to genetic factors that also influence trait $Y$. Dividing $B_{2}$ by the corresponding phenotypic group correlation provides a measure of the proportion of the covariance that can be attributed to genetic factors, called bivariate heritability. ${ }^{23}$

Since bivariate DeFries-Fulker extreme analyses are bidirectional, the analysis for the opposite direction has to be examined separately. The genetic correlation ${ }^{24}$ (the extent to which deficits on trait $X$ and deficits on trait $Y$ are affected by the same set of genes) can be derived as:

$$
r_{\mathrm{g}}(X Y)=\sqrt{ }\left(B_{2(X Y)}\right)\left(B_{2(Y X)}\right) /\left(B_{2(X)}\right)\left(B_{2(Y)}\right)
$$


A genetic correlation of 1.0 suggests complete genetic overlap; a correlation of 0.0 indicates that the traits are affected by two separate sets of genes.

If the transformed $\mathrm{DZ}$ co-twin means are less than half the $\mathrm{MZ}$ co-twin means, non-additive genetic effects might play a role (although sibling interaction effects could also apply). Because the power in DeFries-Fulker analyses is limited to distinguishing non-additive from additive genetic influences, only broad heritability is examined in this study. When the data suggested non-additive effects (when the estimate for $h_{\mathrm{g}}^{2}$ or $B_{2}$ exceeded the estimate of the transformed MZ co-twin mean), $h_{\mathrm{g}}^{2}$ or $B_{2}$ were based on the estimated value of the transformed MZ co-twin mean.

\section{Results}

The distributions of the IQ and academic achievement scores were approximately normal; the CAST scores were slightly skewed (skewness statistics were 1.00 (parent ratings) and 1.47 (teacher ratings)). The untransformed scores were used in subsequent analyses, since previous DeFries-Fulker extremes analyses using the CAST showed that data transformation did not affect the results. ${ }^{7}$ The $5 \%$ with the most extreme (highest) scores on the parent-rated CAST obtained scores $\geqslant 1.83$ standard deviations above the population mean, equivalent to CAST scores $\geqslant 11.83$. The $5 \%$ with the most extreme (lowest) scores on the measure of IQ scored $\leqslant 1.68$ standard deviations (age 7) and 1.85 standard deviations (age 9) below the population mean. Mean CAST scores in children with autism-spectrum conditions were well above the clinical cut-off (mean 19.17, s.d. $=5.11$ ), and CAST total and subscale scores were significantly higher than the population mean (all $P<0.001$ ). Scores for IQ (mean -0.69 , s.d. $=0.12$ ) and academic achievement (mean -1.51 , s.d. $=1.60$ ) were significantly lower than the population mean $(F(1,9986)=26.86$, $P<0.001$ and $F(1,11217)=213.80, \quad P<0.001)$, although these descriptive statistics should be interpreted with care since IQ and academic achievement data were only available for 51 and 84 children with autism-spectrum conditions respectively.

The highest-scoring $5 \%$ on the parent-reported CAST were more likely to perform in the bottom $5 \%$ on the IQ test $\left(\chi^{2}(1)=42.985, P<0.001\right.$, odds ratio $\left.(\mathrm{OR})=4.32\right)$ and to show low academic achievement $\left(\chi^{2}(1)=60.876, P<0.001\right.$, OR $\left.=4.44\right)$. These odds ratios increased to 6.32 and 7.51 respectively in children who scored at or above the CAST cut-off. Extremely high scorers on the teacher-reported CAST were not significantly more likely to have low IQ scores $\left(\chi^{2}(1)=1.718, P=0.083\right.$, OR $\left.=1.76\right)$ but did show an increased risk for poor academic achievement $\left(\chi^{2}(1)=78.979\right.$, $P<0.001, \mathrm{OR}=6.76$ ).

The phenotypic correlations between parent- and teacherrated autistic traits and IQ and academic achievement were all negative and ranged between -0.07 and -0.24 for the full-range scores and between -0.01 and -0.40 for the phenotypic group correlations in the 5\% extremes, suggesting that the association between number of autistic traits and intellectual disability (as indexed by low IQ/academic achievement) was modest. Both the full-range correlations and the phenotypic group correlations were similar in boys and girls (difference in $r \leqslant 0.05$, online Table DS1), yielding no evidence for a gender effect on the association. To maximise power, all subsequent analyses were conducted for both genders combined. Phenotypic group correlations were also calculated for 15\%, 2\% and 1\% cut-offs (online Table DS1). All associations between autistic traits and IQ were similar, suggesting that the magnitude of the relationship was linear across the sample. For academic achievement, there was a trend in which the phenotypic group correlations were somewhat stronger, with more extreme cut-offs for academic achievement.
Univariate DeFries-Fulker analyses (Table 1) showed high group heritability for parent- and teacher-rated CAST scores $\left(h_{\mathrm{g}}^{2}=0.71\right.$ and 0.65 respectively) and academic achievement $\left(h^{2}=0.85\right.$ at both ages), and moderate group heritability for IQ $\left(h^{2}{ }_{\mathrm{g}}=0.31\right.$ (age 7) and 0.44 (age 9)). Univariate DeFries-Fulker analyses have been reported previously ${ }^{7,25}$ and are therefore not discussed in detail here. In the bivariate models, transformed DZ co-twin scores consistently showed a stronger regression to the population mean than MZ co-twin scores, suggesting genetic effects on the overlap between extreme traits. The $B_{2}$ estimates were negligible for the association between IQ and teacher-rated CAST and modest for all other associations. Dividing each $B_{2}$ estimate by the corresponding phenotypic group correlation (bivariate heritability) showed that the modest phenotypic association between extreme autistic traits and intellectual disability was mainly accounted for by genetic effects. For example, in the group selected for extremely low IQ, $86 \%$ of the association with parent-reported CAST scores was explained by genetic factors $(-0.19 /-0.22=0.86)$. The bivariate heritability estimates were high for all measures, apart from the analyses between extremely low IQ and teacher-rated autistic traits. However, the genetic correlations were only modest. The genetic correlations between extreme parent-rated autistic traits and low IQ or poor academic achievement were 0.44 and 0.31 . The genetic correlations using teacher-rated CAST scores were 0.04 and 0.38 . What these results mean is that although genetic factors are largely responsible for the phenotypic association between autistic traits and low IQ/ academic achievement, most of the genetic effects on autistic traits and on IQ/academic achievement are independent.

Next we explored whether the relation between extreme autistic traits and intellectual disability varied for the different features of the autism triad. Both the full-range phenotypic correlations and the phenotypic group correlations indicated that the association between extreme autistic traits and intellectual disability is mainly explained by CAST items assessing communication difficulties (online Table DS2). Examination of the communication impairments items suggested that the observed association was not simply due to overlapping item content. The communication impairments items primarily assess difficulties with pragmatic communication (e.g. 'Does s/he tend to take things literally?') and do not directly assess (verbal) IQ. Repeating the DeFries-Fulker extremes analyses using just the communication impairments subscale yielded similar results to the CAST total analyses (online Table DS3). The genetic correlation between parent-rated communication impairments and intellectual disability was 0.48 when assessed using IQ scores and 0.33 using academic achievement scores. The genetic correlations between these measures and teacher-rated communication impairments were 0.22 and 0.50 respectively.

Lastly, we explored whether a discrepancy between IQ scores and academic achievement is related to number of autistic traits. Difference scores between IQ and academic achievement were correlated with parent and teacher CAST scores. Higher IQ scores relative to academic achievement correlated significantly with parent-reported communication impairments $(r=0.06, P<0.01)$ and teacher-reported CAST total $(r=0.14, P<0.01)$, social impairments $(r=0.13, P<0.01)$ and communication impairments scores $(r=0.17, P<0.01)$.

\section{Discussion}

\section{Modest genetic correlation between extreme autistic traits and intellectual disability}

This paper reports the first population-based study testing the association between extreme autistic traits and intellectual 


\begin{tabular}{|c|c|c|c|c|c|c|c|c|c|c|c|c|}
\hline & \multirow{2}{*}{$\begin{array}{l}\text { Probands, } \\
n\end{array}$} & \multicolumn{3}{|c|}{ Univariate } & \multicolumn{4}{|c|}{ Bivariate (IQ/academic achievement) } & \multicolumn{4}{|c|}{ Bivariate (CAST) } \\
\hline & & Proband & Co-twin & $h^{2} \mathrm{~g}(95 \% \mathrm{Cl})$ & Proband & Co-twin & $B_{2}(95 \% \mathrm{Cl})$ & Bivariate $h_{\mathrm{g}}^{2}$ & Proband & Co-twin & $B_{2}(95 \% \mathrm{Cl})$ & Bivariate $h_{\mathrm{g}}^{2}$ \\
\hline \multirow{2}{*}{\multicolumn{13}{|c|}{$\begin{array}{l}\text { Parent CAST Total age } 8 \\
\text { Standardised }\end{array}$}} \\
\hline & & & & & & & & & & & & \\
\hline $\mathrm{MZ}$ & 201 & 2.79 & 1.99 & & & & & & & & & \\
\hline DZ & 208 & 2.79 & 0.51 & & & & & & & & & \\
\hline \multicolumn{13}{|c|}{ Transformed } \\
\hline $\mathrm{MZ}$ & 201 & 1.00 & 0.71 & & & & & & & & & \\
\hline $\mathrm{DZ}$ & 208 & 1.00 & 0.18 & $\begin{array}{c}0.71 \\
\text { (0.62 to } 0.80)\end{array}$ & & & & & & & & \\
\hline \multicolumn{13}{|c|}{$\begin{array}{l}\text { IQ age } 7 \\
\text { Standardised }\end{array}$} \\
\hline $\mathrm{MZ}$ & 174 & -2.12 & -1.39 & & 0.42 & 0.41 & & & -0.58 & -0.53 & & \\
\hline DZ & 172 & -2.16 & -1.08 & & 0.43 & 0.09 & & & -0.31 & -0.02 & & \\
\hline \multicolumn{13}{|c|}{ Transformed } \\
\hline $\mathrm{MZ}$ & 174 & 1.00 & 0.66 & & -0.20 & -0.19 & & & -0.24 & -0.22 & & \\
\hline DZ & 172 & 1.00 & 0.50 & $\begin{array}{c}0.31 \\
(0.11 \text { to } 0.51)\end{array}$ & -0.20 & -0.04 & $\begin{array}{c}-0.19 \\
(-0.29 \text { to }-0.09)\end{array}$ & 0.86 & -0.12 & -0.01 & $\begin{array}{c}-0.22 \\
(-0.33 \text { to }-0.11)\end{array}$ & 1.00 \\
\hline \multicolumn{13}{|c|}{$\begin{array}{l}\text { Academic achievement age } 7 \\
\text { Standardised }\end{array}$} \\
\hline $\mathrm{MZ}$ & 218 & -2.60 & -2.21 & & 0.58 & 0.48 & & & -0.91 & -0.87 & & \\
\hline DZ & 157 & -2.58 & -1.08 & & 0.65 & 0.30 & & & -0.68 & -0.26 & & \\
\hline \multicolumn{13}{|c|}{ Transformed } \\
\hline$M Z$ & 218 & 1.00 & 0.85 & & -0.23 & -0.19 & & & -0.36 & -0.35 & & \\
\hline DZ & 157 & 1.00 & 0.42 & $\begin{array}{c}0.85 \\
(0.78 \text { to } 0.92)\end{array}$ & -0.25 & -0.12 & $\begin{array}{c}-0.17 \\
(-0.38 \text { to } 0.04)\end{array}$ & 0.68 & -0.26 & -0.10 & $\begin{array}{c}-0.35 \\
(-0.47 \text { to }-0.23)\end{array}$ & 1.00 \\
\hline \multicolumn{13}{|c|}{$\begin{array}{l}\text { Teacher CAST Total age } 9 \\
\text { Standardised }\end{array}$} \\
\hline $\mathrm{MZ}$ & 90 & 2.91 & 2.03 & & & & & & & & & \\
\hline DZ & 90 & 2.90 & 1.07 & & & & & & & & & \\
\hline \multicolumn{13}{|c|}{ Transformed } \\
\hline$M Z$ & 90 & 1.00 & 0.70 & & & & & & & & & \\
\hline DZ & 90 & 1.00 & 0.37 & $\begin{array}{c}0.65 \\
(0.32 \text { to } 0.98)\end{array}$ & & & & & & & & \\
\hline \multicolumn{13}{|c|}{$\begin{array}{l}\text { IQ age } 9 \\
\text { Standardised }\end{array}$} \\
\hline $\mathrm{MZ}$ & 110 & -2.26 & -1.62 & & 0.12 & 0.01 & & & -0.09 & -0.10 & & \\
\hline DZ & 113 & -2.26 & -1.12 & & 0.27 & -0.02 & & & -0.07 & 0.09 & & \\
\hline \multicolumn{13}{|c|}{ Transformed } \\
\hline$M Z$ & 110 & 1.00 & 0.72 & & -0.06 & -0.01 & & & -0.03 & -0.04 & & \\
\hline $\mathrm{DZ}$ & 113 & 1.00 & 0.49 & $\begin{array}{c}0.44 \\
(0.23 \text { to } 0.65)\end{array}$ & -0.12 & 0.01 & $\begin{array}{c}-0.01 \\
(-0.13 \text { to } 0.11)\end{array}$ & 0.08 & -0.02 & 0.03 & $\begin{array}{c}-0.04 \\
(-0.15 \text { to } 0.07)\end{array}$ & 0.80 \\
\hline \multicolumn{13}{|c|}{$\begin{array}{l}\text { Academic achievement age } 9 \\
\text { Standardised }\end{array}$} \\
\hline $\mathrm{MZ}$ & 85 & -2.20 & -1.86 & & 0.95 & 0.86 & & & -0.61 & -0.59 & & \\
\hline DZ & 72 & -2.22 & -0.88 & & 0.88 & 0.20 & & & -0.54 & -0.14 & & \\
\hline \multicolumn{13}{|c|}{ Transformed } \\
\hline$M Z$ & 85 & 1.00 & 0.85 & & -0.43 & -0.40 & & & -0.21 & -0.20 & & \\
\hline DZ & 72 & 1.00 & 0.40 & $\begin{array}{c}0.85 \\
(0.75 \text { to } 0.95)\end{array}$ & -0.40 & -0.09 & $\begin{array}{c}-0.40 \\
(-0.55 \text { to }-0.25)\end{array}$ & 1.00 & -0.19 & -0.05 & $\begin{array}{c}-0.20 \\
(-0.31 \text { to }-0.09)\end{array}$ & 1.00 \\
\hline
\end{tabular}

disability (defined in terms of low IQ/academic achievement). Although the risk of showing poor performance on tests of IQ and academic achievement was significantly increased in children with extreme autistic traits, our results suggest that the association between extreme autistic traits and intellectual disability is only modest. There was a degree of genetic overlap between extreme autistic traits and intellectual disability, as indicated by modest genetic correlations. Since autistic traits are highly heritable 7,26 there is also substantial genetic specificity for autistic traits.

These results are in agreement with findings from family studies indicating that (severe) intellectual disability is not part of the broader autism phenotype observed in relatives of autistic probands. Although high intraclass correlations are observed between IQ scores in affected children from the same family, ${ }^{27,28}$ there is no evidence for a familial loading for intellectual disability in unaffected family members of autism probands, and the correlation between IQs of affected and unaffected family members is low. ${ }^{29-31}$ Also, in autism-spectrum conditions, unlike most severe developmental disorders (e.g. Williams syndrome, Down syndrome), there is no 'capping' of IQ, and measured IQ can be extremely high. ${ }^{32,33}$

Clinical studies of the phenotypic association between autism symptom severity, as indexed by Autism Diagnostic Observation Schedule $(\mathrm{ADOS})^{34}$ and Autism Diagnostic Interview-Revised $(\mathrm{ADI}-\mathrm{R})^{35}$ scores, and intellectual functioning generally found modest to moderate correlations between social impairments and communication impairments and measures of IQ. ${ }^{36-38}$ Results for symptoms of restricted repetitive behaviours and interests varied, depending on the sample under investigation and the type of restricted repetitive behaviours and interests studied. ${ }^{36-8}$ Several family studies indicated an increased rate of social and communication deficits in relatives of individuals with autism. ${ }^{39}$ There is evidence to suggest that relatives who show communication difficulties also tend to have lower IQs. ${ }^{29,30,40}$ These studies are in line with our finding that the association between autistic traits and intellectual disability was mainly driven by communication difficulties.

\section{Academic achievement $\boldsymbol{v}$. IQ in children with extreme autistic traits}

Our phenotypic analyses suggested that the association between poor academic achievement and autistic traits became stronger the more stringently the cut-off for extreme groups was set. This trend was not observed in the analyses between autistic traits and IQ, for which the magnitude of the full-range phenotypic correlations and phenotypic group correlations was similar regardless of the cut-off. Analyses exploring discrepancies between IQ scores and teacher-rated academic achievement suggested that teachers may underestimate the academic abilities of children with social 
and communication difficulties. Children with such problems may struggle to show their full cognitive potential in the classroom. These results mirror findings from clinical studies that report attenuated academic achievement relative to IQ in individuals with autism-spectrum conditions. ${ }^{2}$

\section{Methodological considerations}

The current study defined extreme autistic traits as the highestscoring $5 \%$ of a large community sample assessed on a continuous measure of autistic traits. This selection included children scoring $\geqslant 11.83$ on the parent-reported CAST. Children with a diagnosis of autism-spectrum conditions typically ${ }^{5}$ obtain parental CAST scores $\geqslant 15$ and our extreme group is therefore likely to include less extreme cases than a clinical sample. Similarly, the lowestscoring $5 \%$ on a measure of IQ and academic achievement were selected. Although the IQ and academic achievement scores in these extreme groups were markedly low (mean academic achievement scores were 2.20-2.60 standard deviations below the population mean; IQ scores were 2.12-2.26 standard deviations below the population mean, corresponding to standardised IQs of approximately 67), it should be acknowledged that this sample included few children with severe intellectual disabilities. Our results cannot therefore be generalised to individuals with severe or profound intellectual disability, in whom the aetiology of autism may be different. ${ }^{4}$ In about $10-20 \%$ of cases, autism-spectrum condition can be accounted for by known medical conditions, defined mutations or gross chromosomal abnormalities ${ }^{41}$ and the affected individuals are likely also to have intellectual disability. Our results are only informative for the idiopathic cases (accounting for the remaining 80-90\%) in which the risk for autism may be influenced by common genetic variants.

The large scale of this study did not permit detailed investigation of the relative strengths and weaknesses in cognitive functioning. The IQ tests were administered by telephone at age 7. Children with many autistic traits, particularly children with communication difficulties, may find it hard to perform well using this assessment procedure. However, similar correlations were found using the academic achievement data and at age 9 (when test booklets were used), strengthening our confidence in the validity of the IQ measure at age 7. At age 9 data were available for a smaller number of twins, and most children with autism-spectrum conditions were excluded at this age to avoid over-testing. We feel that these data are still valuable as the results show remarkable consistency between raters and across age, indicating that these findings are neither rater- nor age-specific.

\section{Implications}

This study has implications for future genetic studies of autism. Our results indicate that in a community-based sample the liability to extreme autistic traits is substantially genetically independent of the vulnerability to impaired intellectual functioning. In so far as there is genetic overlap, this link is likely to be found in genes affecting communication abilities. Genes involved in neurodevelopment are probably important in certain forms of autism-spectrum conditions, ${ }^{42}$ particularly in individuals with severe intellectual disability. However, these genes are unlikely to be the sole explanation of the complex aetiology of autism. Our study suggests that genetic variants that do not affect general intellectual abilities also play a role.

Our finding of a limited association between autistic traits and intellectual disability contrasts with clinical studies reporting a high prevalence of intellectual disability in autism. ${ }^{1}$ This discrepancy may be explained, in part, by clinical ascertainment bias. ${ }^{4}$ Individuals with extreme autistic traits and intellectual disability may be more likely to be referred to the clinic. The number of individuals with autism-spectrum conditions with normal IQ may thus be underreported. Health and education professionals may need to be made more aware that autism-spectrum conditions can occur without intellectual disability to ensure that all individuals warranting a diagnosis are detected.

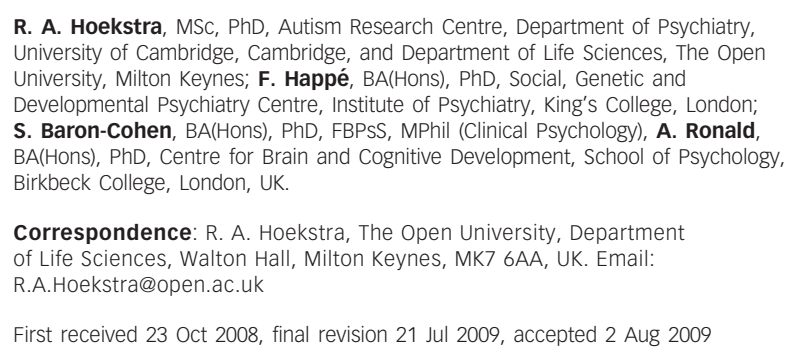

Correspondence: R. A. Hoekstra, The Open University, Department

of Life Sciences, Walton Hall, Milton Keynes, MK7 6AA, UK. Email:

R.A.Hoekstra@open.ac.uk

First received 23 Oct 2008, final revision 21 Jul 2009, accepted 2 Aug 2009

\section{Funding}

The Twins Early Development Study is funded by MRC grant G0500079 to Professor Robert Plomin. R.A.H. is financially supported by the Netherlands Organisation for Scientific Research (NWO Rubicon).

\section{Acknowledgements}

We gratefully acknowledge the twin families for their ongoing participation. We are indebted to Professor Plomin for the use of the TEDS data.

\section{References}

1 Fombonne E. Past and future perspectives on autism epidemiology. In Understanding Autism, from Basic Neuroscience to Treatment (eds so Moldin, JLR Rubenstein): 25-48. Taylor \& Francis, 2006.

2 Shea V, Mesibov G. Adolescents and adults with autism. In Handbook of Autism and Pervasive Developmental Disorders (5th edn) (eds FR Volkmar, R Paul, A Klin \& D Cohen): 288-311. John Wiley \& Sons, 2005.

3 Chakrabarti S, Fombonne E. Pervasive developmental disorders in preschool children: confirmation of high prevalence. Am J Psychiatry 2005; 162: 1133-41.

4 Skuse DH. Rethinking the nature of genetic vulnerability to autistic spectrum disorders. Trends Genet 2007; 23: 387-95.

5 Scott FJ, Baron-Cohen S, Bolton P, Brayne C. The CAST (Childhood Asperger Syndrome Test): preliminary development of a UK screen for mainstream primary-school-age children. Autism 2002; 6: 9-31.

6 Baron-Cohen S, Wheelwright S, Skinner R, Martin CE. The Autism Spectrum Quotient (AQ): Evidence from Asperger syndrome/high functioning autism, males and females, scientists and mathematicians. J Autism Dev Disord 2001; 31: 5-17.

7 Ronald A, Happé F, Price TS, Baron-Cohen S, Plomin R. Phenotypic and genetic overlap between autistic traits at the extremes of the general population. J Am Acad Child Adolesc Psychiatry 2006; 45: 1206-14.

8 Ronald A, Happé F, Plomin R. A twin study investigating the genetic and environmental aetiologies of parent, teacher and child ratings of autistic-like traits and their overlap. Eur Child Adolesc Psychiatry 2008; 17: 473-83.

9 Oliver BR, Plomin R. Twins' Early Development Study (TEDS): a multivariate, longitudinal genetic investigation of language, cognition, and behavior problems from childhood through adolescence. Twin Res Hum Genet 2007; 10: 96-105

10 Price TS, Freeman B, Craig IW, Petrill SA, Ebersole L, Plomin R. Infant zygosity can be assigned by parental report questionnaire data. Twin Res 2000; 3: 129-33.

11 Ronald A, Happé F, Bolton P, Butcher LM, Price TS, Wheelwright S, et al. Genetic heterogeneity between the three components of the autism spectrum: a twin study. J Am Acad Child Adolesc Psychiatry 2006; 45: 691-9.

12 American Psychiatric Association. Diagnostic and Statistical Manual of Mental Disorder (4th edn) (DSM-IV). APA, 1994. 
13 Williams J, Allison C, Scott F, Stott C, Bolton P, Baron-Cohen S, et al. The Childhood Asperger Syndrome Test (CAST): test-retest reliability. Autism 2006; 10: 415-27.

14 Wechsler D. Wechsler Intelligence Scale for Children (3rd edn) (WISC-III-UK) The Psychological Corporation, 1992.

15 McCarthy D. McCarthy Scales of Children's Abilities. The Psychological Corporation, 1972

16 Petrill S, Rempell J, Oliver B, Plomin R. Testing cognitive abilities by telephone in a sample of 6-to-8-year olds. Intelligence 2002; 30: 353-60.

17 Lohman D, Hagen E, Thorndike R. Cognitive Abilities Test (3rd edn) (CAT3). nferNELSON, 2003

18 Goodman R, Ford T, Richards $\mathrm{H}$, Gatward R, Meltzer $\mathrm{H}$. The Development and Well-Being Assessment: description and initial validation of an integrated assessment of child and adolescent psychopathology. J Child Psychol Psychiatry 2000; 41: 645-55.

19 Neale MC, Boker SM, Xie G, Maes HH. Mx: Statistical Modeling. Virginia Commonwealth University Department of Psychiatry, 2006.

20 Plomin R. Genetic risk and psychosocial disorders: links between the norma and abnormal. In Biological Risk Factors for Psychosocial Disorders (eds M Rutter \& P Casaer): 101-38. Cambridge University Press, 1991.

21 DeFries JC, Fulker DW. Multiple regression analysis of twin data: etiology of deviant scores versus individual differences. Acta Genet Med Gemellol (Roma) 1988; 37: 205-16.

22 Light JG, DeFries JC. Comorbidity of reading and mathematics disabilities: genetic and environmental etiologies. J Learn Disabil 1995; 28: 96-106.

23 Plomin R, DeFries JC. Multivariate behavioral genetic analysis of twin data on scholastic abilities. Behav Genet 1979; 9: 505-17

24 Knopik VS, Alarcón M, DeFries JC. Comorbidity of mathematics and reading deficits: evidence for a genetic etiology. Behav Genet 1997; 27: 447-53.

25 Kovas Y, Haworth CMA, Dale PS, Plomin R. The genetic and environmental origins of learning abilities and disabilities in the early school years. Monogr Soc Res Child Dev 2007; 72: 1-144.

26 Hoekstra RA, Bartels M, Verweij CJH, Boomsma DI. Heritability of autistic traits in the general population. Arch Pediatr Adolesc Med 2007; 161: 372-7.

27 Goin-Kochel RP, Mazefsky CA, Riley BP. Level of functioning in autism spectrum disorders: phenotypic congruence among affected siblings. J Autism Dev Disord 2008; 38: 1019-27.

28 MacLean JE, Szatmari P, Jones MB, Bryson SE, Mahoney WJ, Bartolucci G, et al. Familial factors influence level of functioning in pervasive developmental disorder. J Am Acad Child Adolesc Psychiatry 1999; 38: 746-53.

29 Fombonne E, Bolton P, Prior J, Jordan H, Rutter M. A family study of autism: cognitive patterns and levels in parents and siblings. J Child Psychol Psychiatry 1997; 38: 667-83.
30 Folstein SE, Santangelo SL, Gilman SE, Piven J, Landa R, Lainhart J, et al. Predictors of cognitive test patterns in autism families. J Child Psychol Psychiatry 1999; 40: 1117-28.

31 Szatmari $\mathrm{P}$, Jones MB, Holden J, Bryson S, Mahoney W, Tuff L, et al. High phenotypic correlations among siblings with autism and pervasive developmental disorders. Am J Med Genet 1996; 67: 354-60.

32 Dawson $M$, Soulières I, Gernsbacher MA, Mottron L. The level and nature of autistic intelligence. Psychol Sci 2007; 18: 657-62.

33 Scheuffgen K, Happé F, Anderson M, Frith U. High "intelligence," low "IQ"? Speed of processing and measured IQ in children with autism. Dev Psychopathol 2000; 12: 83-90.

34 Lord C, Risi S, Lambrecht L, Cook EH Jr, Leventhal BL, DiLavore PC, et al. The Autism Diagnostic Observation Schedule - Generic: a standard measure of social and communication deficits associated with the spectrum of autism. J Autism Dev Disord 2000; 30: 205-23.

35 Lord C, Rutter M, Le Couleur A. Autism Diagnostic Interview - Revised: a revised version of a diagnostic interview for caregivers of individuals with possible pervasive developmental disorders. J Autism Dev Disord 1994; 24: $659-85$

36 Hus V, Pickles A, Cook EH, Risi S, Lord C. Using the autism diagnostic interview-revised to increase phenotypic homogeneity in genetic studies of autism. Biol Psychiatry 2007; 61: 438-48.

37 Georgiades S, Szatmari P, Zwaigenbaum L, Duku E, Bryson S, Roberts W, et al. Structure of the Autism Symptom Phenotype: a proposed multidimensional model. J Am Acad Child Adolesc Psychiatry 2007; 46: 188-96.

38 Spiker D, Lotspeich L, Dimiceli S, Myers RM, Risch N. Behavioral phenotypic variation in autism multiplex families: evidence for a continuous severity gradient. Am J Med Genet 2002; 114: 129-36.

39 Bailey A, Palferman S, Heavey L, Le Couteur A. Autism: the phenotype in relatives. J Autism Dev Disord 1998; 28: 369-92.

40 Bishop DVM, Maybery M, Wong D, Maley A, Hallmayer J. Characteristics of the broader phenotype in autism: a study of siblings using the children's communication checklist-2. Am J Med Genet B Neuropsychiatr Genet 2006; 141B: $117-22$

41 Abrahams BS, Geschwind DH. Advances in autism genetics: on the threshold of a new neurobiology. Nat Rev Genet 2008; 9: 341-55.

42 Persico AM, Bourgeron T. Searching for ways out of the autism maze: genetic, epigenetic and environmental clues. Trends Neurosci 2006; 29 : 349-58.

\section{Global warming}

words

\section{H. Steven Moffic}

Much scientific consensus has developed that global warming is a major threat to the well-being of our planet and ourselves. This danger includes mental health. Violence, trauma and anxiety are all projected to increase. Psychology has also contributed to the genesis and delayed responsiveness to global warming, given the use of denial, narcissism, and fear of change on the part of politicians and citizens. Given the importance of psychiatry for this social problem, psychiatrists should be at the forefront of 'going green' in terms of advocacy, modelling and solutions. We are not yet, but our ethical duty requires more. 